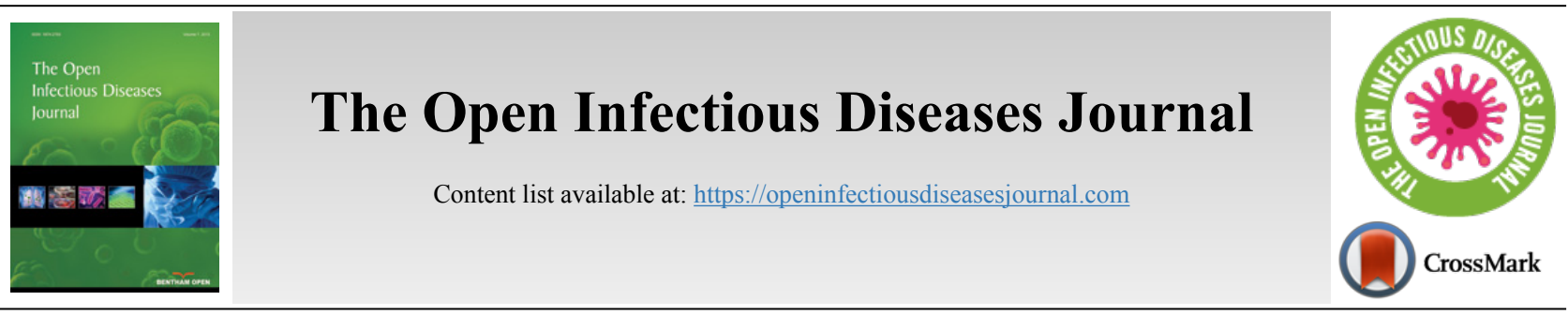

RESEARCH ARTICLE

\title{
Nutritional Status of Patients Co-Infected with TB/HIV During Tuberculosis Treatment at Conakry-Guinea UHC
}

Mamadou Saliou Sow ${ }^{1,2,3,}$, Alioune Camara ${ }^{3,4}$, Sidikiba Sidibé ${ }^{4}$, Ibrahima Kaba ${ }^{1}$, Nestor Niouma Leno ${ }^{4}$, Boubacar Djelo Diallo $^{5}$, Ibrahima Camara ${ }^{2}$ and Lansana Mady Camara ${ }^{5}$

${ }^{1}$ Department of Infectious and Tropical Diseases, University Hospital Center of Conakry, Conakry, Guinea

${ }^{2}$ Department of Epidemiology, Guinea Infectious Disease Research and Training Center (CERFIG), University of Conakry, Conakry, Guinea

${ }^{3}$ Faculty of Health Sciences and Techniques, African Center of Excellence for Prevention and Control of Communicable Diseases (CEA-PCMT), Gamal Abdel Nasser University, Conakry, Guinea

${ }^{4}$ Department of Public Health, Faculty of Health Sciences and Techniques, Gamal Abdel Nasser University Conakry, Guinea

${ }^{5}$ Department of Pneumology, Conakry University Hospital Center, Conakry, Guinea

\begin{abstract}
:
Introduction:

The aim was to assess weight gain during tuberculosis treatment in patients co-infected with tuberculosis and HIV.

Methods:

Tuberculosis patients co-infected with HIV and undergoing tuberculosis treatment in the pneumophtisiology and infectious and tropical diseases departments of the CHU in Conakry were included.

Results:

562 patients were included, with a mean age of $35.6 \pm 11.3$ years, and 52.5\% were women. The average Body Mass Index [BMI] at baseline was $17.83 .3 \mathrm{~kg} / \mathrm{m}^{2} .71 .5 \%$ of patients had a favorable result and $28.5 \%$ had an unfavorable result [death, abandonment]. Healed and lost patients gained an average of $2.6 \mathrm{~kg}$ and $0.1 \mathrm{~kg}$ respectively. Deceased patients lost an average of $3.6 \mathrm{~kg}$. The weight variations of the cured patients were different from those of the deceased $[\mathrm{p}<0.001]$. A weight gain of $5 \%$ after 6 months of treatment was associated with the treatment site $[\mathrm{OR}=3.81$; $95 \%$ CI 1.08 to 13.45 ], alcohol consumption [OR=10.33; 95\% CI 1.20 to 89.16 ], malnutrition before treatment [OR=2.72; $95 \%$ CI 1.43 to 5.17 ] and the form of tuberculosis [OR=3.27; $95 \%$ CI 1.15 to 9.33$]$.

Conclusion:

Newly diagnosed patients co-infected with TB-HIV at Conakry's CHU are often malnourished. Weight gain during treatment seems to be a reliable
\end{abstract} indicator of the overall response to treatment.

Keywords: TB-HIV, Patients, Co-infection, Nutrition, Conakry, Guinea.

\begin{tabular}{|l|l|l|l|} 
Article History & Received: December 2, 2020 & Revised: April 12, 2021 & Accepted: June 7, 2021
\end{tabular}

\section{INTRODUCTION}

The number of people infected with Mycobacterium tuberculosis is estimated at 1.86 billion, or nearly one-third of the world's population. The majority of these individuals live in developing countries where the Human Immunodeficiency Virus [HIV] is a major public health problem [1].

\footnotetext{
* Address correspondence to this author at Department of Infectious and Tropical Diseases, University Hospital Center of Conakry, Conakry, Guinea; Mailing address 234, Tel: +224622913830; E-mail: smsaliou@gmail.com
}

It is a global burden and the World Health Organization (WHO) has estimated that there are 9 million active tuberculosis cases and 1.5 million deaths from tuberculosis worldwide.

In 2013, WHO estimated that $62 \%$ of newly diagnosed TB patients in South Africa are HIV-positive [2, 3]. The HIV pandemic remains the leading cause of morbidity and mortality in sub-Saharan Africa and accounts for $31 \%$ of new adult TB cases. Malnutrition and weight loss are associated with HIV and tuberculosis co-infection. Tuberculosis can potentially 
exacerbate weight loss during co-infection [4]. Several crosssectional studies suggest that patients with tuberculosis are at high risk of deficiency of vitamin A, thiamin, vitamin B6, folic acid, vitamin E, and zinc [4]. Consistent risk factors for early death include delayed initiation of antiretroviral therapy, low Body Mass Index (BMI), and the presence of opportunistic infections [5].

Among these infections, tuberculosis has long been associated with malnutrition, a factor that plays a role in the reactivation of latent tuberculosis infection [1]. Weight loss has always been a part of the natural history of HIV infection, and the wasting syndrome is one of the criteria for classifying disease severity used by the WHO and the Centers for Disease Control and Prevention [6]. Undernutrition increases susceptibility to infection, including tuberculosis. In addition, malnutrition is associated with more severe pulmonary manifestations of tuberculosis and poorer outcomes after tuberculosis treatment [6]. In patients with HIV, tuberculosis patients have a lower BMI than people without tuberculosis [7].

In Guinea, patients with HIV-TB were formerly followed in the pulmonary department. Since 2009, a TB management focal point has been established in the Infectious Diseases (SMIT) Department of Donka National Hospital. However, there is no nutrition unit in these centers and we do not have data on the nutritional aspects of people co-infected with TBHIV. It is in this context that we undertook this study.

This study aimed to evaluate weight gain during tuberculosis treatment in TB/HIV co-infected patients.

\section{METHODS}

\subsection{Setting and Type of Study}

Our study took place in the Pneumophtisiology, Infectious and Tropical Diseases Department (SMIT) of the University Hospital Center (CHU) in Conakry. The Pneumophtisiology Department is the reference center for tuberculosis management. It includes a Mycobacteriology laboratory and an outpatient treatment center (CTA). The SMIT is also one of the referral and case management services for tuberculosis/HIV co-infections. It was a multi-center historical cohort study of patients diagnosed with tuberculosis and HIV co-infection from March 1, 2013 to April 30, 2015.

\subsection{Study Population}

We have conducted exhaustive recruitment of the files of TB/HIV co-infected patients followed in the Pneumophtisiology and SMIT departments. Newly diagnosed TB/HIV co-infected patients undergoing tuberculosis therapy in the Pneumophtisiology and Infectious and Tropical Diseases departments of the CHU of Conakry constituted the study population. Thus, HIV co-infected tuberculosis patients aged 15 years and older who started tuberculosis treatment were included in the study. Excluded were HIV co-infected tuberculosis patients who relapsed or failed, or who should be transferred to other sites for follow-up. In Guinea, according to the guidelines of the National Tuberculosis Control Program [8] all patients at the time of diagnosis of tuberculosis should routinely be screened for HIV [if unknown]. New cases of tuberculosis were given the six-month regimen of Rifampicin (R), Isoniazid (H) Ethambutol (E), and Pyrazinamide (Z) for two months, followed by Rifampicin $(\mathrm{R})$ and Isoniazid $(\mathrm{H})$ for four months.

\subsection{Data Collection and Definition of Variables}

A standardized form was used to collect data from patient medical records, logbooks and registers available at the sites. Data collection was conducted at the beginning of each patient's tuberculosis treatment, and then monthly. The data collected included socio-demographic characteristics [age, gender, employment, and marital status], lifestyle [alcohol, tobacco] and body mass index. The diagnosis of tuberculosis was made on direct or indirect grounds. The types of tuberculosis were categorized as pulmonary and extrapulmonary.

The presence of other opportunistic infections (Kaposi's disease, candidiasis, and toxoplasmosis) in addition to tuberculosis was categorized as less than two and more than one. The presence of antiretroviral therapy at the start of tuberculosis treatment was categorized as yes or no. CD4 count was categorized into three groups [missing; $<200$ cells $/ \mathrm{mm}^{3}$; $\geq 200$ cells $/ \mathrm{mm}^{3}$ ]. Underweight was defined as a body mass index $[\mathrm{BMI}]<18.5 \mathrm{~kg} / \mathrm{m}^{2}$ [9]. For this analysis, at the end of 6 months, patients were classified as having a favorable treatment outcome if they were cured or had completed treatment. Unfavorable treatment outcomes included those who were lost to follow-up or died during management. Lost follow-up was defined as those for whom there was no contact with the service before the end of the treatment. A $5 \%$ weight gain was defined as a $5 \%$ increase in baseline weight.

\subsection{Analysis of Data}

The data collected was captured using Epi data 3.1 software and analyzed using SPSS version 24. In the descriptive analysis, proportions with confidence intervals were used to summarize categorical variables; means with confidence intervals and medians with interquartile were used to summarize numerical variables. To identify the factors associated with a weight gain of 5\% during the 6 months of treatment (etiological analysis), we performed a bivariate analysis, then a multivariate analysis (logistic regression). The bivariate analysis between the dependent variable (weight gain) and each of the explanatory variables was done by calculating the gross odds ratio (gross OR), 95\% CI. All explanatory variables with a $p$-value $\geq$ of 0.20 , but whose association with the dependent variable is proven in the literature, were retained for multivariate analysis [logistic regression] and are said to be forced. Weight gain of less than $5 \%$ was used as a reference in the multivariate logistic regression models with the stepwise top-down method. Adjusted Odds ratios were calculated with their confidence intervals and p-values. Explanatory variables with an adjusted OR having a p-value $\leq$ of 0.05 were considered significantly associated with a weight gain of $5 \%$.

\subsection{Ethical Approval}

We have received permission from the department heads to 
proceed with data collection from patient records. The questionnaire was anonymous and confidentiality in data management (use and publication) was respected.

\section{RESULTS}

Five hundred and ninety-four TB/HIV co-infected patients were recruited. Thirty-two patients were excluded from the analysis because no baseline weights were recorded in their records. The remaining 562 patients made up the study population.

Slightly more than half of the 562 patients were female (52\%), less than 35 years of age (56\%), had pulmonary TB $(71.2 \%)$ and followed in the pulmonary department (90.2\%). The mean age of the patients was $35.7 \pm 11.3$.

Prior to tuberculosis treatment, the mean weight and Body Mass Index [BMI] for all patients were $50.8 \mathrm{~kg}(10.1 \mathrm{~kg})$ and $17.8 \mathrm{~kg} / \mathrm{m}^{2}\left(3.3 \mathrm{~kg} / \mathrm{m}^{2}\right)$, respectively. It was noted that $63.7 \%$ of patients were undernourished (BMI $<18.5 \mathrm{~kg} / \mathrm{m}^{2}$ ) prior to treatment.

At the end of TB treatment, the TB/HIV co-infected patients recruited were divided into 402 (71.5\%) with favorable results and $160(28.5 \%)$ with unfavorable results. Of those with unfavorable results, 75 (46.9\%) were lost to follow-up and 85 (53.1\%) were deceased. In Table 1, it appears that the basic characteristics of patients with favorable and unfavorable treatment were similar except for treatment site $(\mathrm{p}<0.001)$, presence of more than one opportunistic infection $(p<0.001)$, CD4 count $(p=00.6)$, and being on antiretroviral therapy $(\mathrm{p}<0.001)$.

Table 2 shows the change in weight according to baseline BMI over the six months of TB treatment. Slight weight loss is observed up to the second month of treatment for all patients, except for those who were not malnourished before treatment; weight loss continues until the third month. Between the third and sixth month of tuberculosis treatment, there is a mean weight gain of $2.75 \mathrm{~kg}$ for all patients, ranging from $1.78 \mathrm{~kg}$ in the non-nutrient poor to $3.25 \mathrm{~kg}$ in the nutrient poor.

The median percent overall cumulative weight gain from baseline to the end of the 6th month of the treatment for TB/HIV co-infected patients was $5.0 \%$ (RDI 0 to 11.1 ). Nearly half $(48.20 \%)$ of TB/HIV co-infected patients followed up to 6 months had a $5 \%$ weight gain at the end of treatment.

In a multivariate logistic regression analysis (Table $\mathbf{3}$ ), a weight gain of more than $5 \%$ after 6 months of treatment was associated with the treatment site $(\mathrm{OR}=3.81 ; 95 \% \mathrm{CI} 1.08$ to 13.45), alcohol consumption ( $\mathrm{OR}=10.33$; $95 \%$ CI 1.20 to 89.16), being malnourished before treatment ( $\mathrm{OR}=2.72 ; 95 \%$ CI 1.43 to 5.17 ) and the form of tuberculosis (OR=3.27; $95 \%$ CI 1.15 to 9.33 ).

Table 1. Characteristics of co-infected tuberculosis and HIV patients by treatment outcome at Conakry University Hospital.

\begin{tabular}{|c|c|c|c|c|}
\hline \multirow{3}{*}{ Variables } & \multirow{3}{*}{$\begin{array}{c}\text { Total } \\
\mathbf{N}=\mathbf{5 6 2}[\%]\end{array}$} & \multicolumn{2}{|c|}{ Treatment outcome } & \multirow[t]{3}{*}{ p-value } \\
\hline & & Favorite & Against & \\
\hline & & $\mathrm{n}=402[\%]$ & $\mathrm{n}=160[\%]$ & \\
\hline Patient monitoring site & & & & $<0.001$ \\
\hline Pneumology & $507[90.2]$ & $388[96.5]$ & $119[74.4]$ & \\
\hline SMIT & $55[9.8]$ & $14[3.5]$ & $41[25.6]$ & \\
\hline Sex & & & & 0.34 \\
\hline Woman & $292[52.0]$ & $214[53.2]$ & 78 [48.8] & \\
\hline Man & $270[48.0]$ & $188[46.8]$ & $82[51.3]$ & \\
\hline Age & & & & 0.27 \\
\hline$\leq 35$ years & $315[56.1]$ & $231[57.6]$ & $84[52.5]$ & \\
\hline$>35$ years & 246 [43.9] & $170[42.4]$ & $76[47.5]$ & \\
\hline Average age $[ \pm \mathrm{ET}]$ & $35.7[ \pm 11.3]$ & $35.4[ \pm 11.4]$ & $36.3[ \pm 11.3]$ & \\
\hline Status matrimonial & & & & 0.63 \\
\hline Married & $339[60.3]$ & $240[59.7]$ & 99 [61.9] & \\
\hline Single & $223[39.7]$ & $162[40.3]$ & $61[38.1]$ & \\
\hline Have a job & & & & 0.24 \\
\hline No & $186[33.2]$ & $127[31.7]$ & 59 [36.9] & \\
\hline Yes & $375[66.8]$ & $274[68.3]$ & $101[63.1]$ & \\
\hline Smoking & & & & 0.44 \\
\hline No & $454[80.8]$ & $328[81.6]$ & $126[78.8]$ & \\
\hline Yes & 108 [19.2] & 74 [18.4] & 34 [21.3] & \\
\hline Alcohol & & & & 0.53 \\
\hline No & 544 [97.7] & $389[97.7]$ & $155[97.5]$ & \\
\hline Yes & $13[2.3]$ & $9[2.3]$ & $4[2.5]$ & \\
\hline Number of Opportunistic Infections & & & & $<0.001$ \\
\hline$<2$ I. opportunistic & 539 [96.3] & $394[98.5]$ & $145[90.6]$ & 0.04 \\
\hline$\geq 2$ I. opportunistic & $21[3.8]$ & $6[1.5]$ & $15[9.4]$ & \\
\hline
\end{tabular}


(Table 1) contd.....

\begin{tabular}{|c|c|c|c|c|}
\hline \multirow[b]{2}{*}{ Variables } & \multirow{2}{*}{$\begin{array}{c}\text { Total } \\
\mathrm{N}=562[\%]\end{array}$} & \multicolumn{2}{|c|}{ Treatment outcome } & \multirow[t]{2}{*}{ p-value } \\
\hline & & Favorite & Against & \\
\hline Average weight $[ \pm \mathrm{ET}]$ & $50.8[ \pm 10.1]$ & $51.3[ \pm 10.0]$ & $49.4[ \pm 10.2]$ & \\
\hline BMI & & & & 0.83 \\
\hline$<18.5 \mathrm{~kg} / \mathrm{m}^{2}$ & $358[63.7]$ & $255[63.4]$ & $103[64.4]$ & \\
\hline$\Rightarrow>18.5 \mathrm{~kg} / \mathrm{m}^{2}$ & $204[36.3]$ & $147[36.6]$ & $57[35.6]$ & \\
\hline Average BMI $[ \pm \mathrm{ET}]$ & $17.8[ \pm 3.3]$ & $18.0[ \pm 3.4]$ & $17.5[ \pm 3.0]$ & \\
\hline CD4 count & & & & 0.006 \\
\hline$\leq 200 \mathrm{cel} / \mathrm{mm}^{3}$ & $192[34.2]$ & $129[32.1]$ & $63[39.4]$ & \\
\hline$>200 \mathrm{cel} / \mathrm{mm}^{3}$ & $151[26.9]$ & $123[30.6]$ & $28[17.5]$ & \\
\hline Missing & $219[39.0]$ & $150[37.3]$ & $69[43.1]$ & \\
\hline Antiretroviral therapy & & & & $<0.001$ \\
\hline Yes & $533[94.8]$ & $394[98.0]$ & 139 [86.9] & \\
\hline No & $29[5.2]$ & $8[2.0]$ & $21[13.1]$ & \\
\hline Tuberculosis Form & & & & 0.16 \\
\hline Pulmonary & $400[71.2]$ & $293[72.9]$ & $107[66.9]$ & \\
\hline Extrapulmonary & $162[28.8]$ & $109[27.1]$ & $53[33.1]$ & \\
\hline
\end{tabular}

Table 2. Analysis of factors associated with weight gain during antiretroviral treatment of tuberculosis and HIV co-infected patients at the Conakry University Hospital of Conakry.

\begin{tabular}{|c|c|c|c|c|c|c|}
\hline \multirow{2}{*}{ Month [effectif] } & \multicolumn{2}{|c|}{ Total } & \multicolumn{2}{|c|}{ BMI $<18.5 \mathrm{~kg} / \mathrm{m}^{2}$} & \multicolumn{2}{|c|}{$\mathrm{BMI} \geq 18.5 \mathrm{~kg} / \mathrm{m}^{2}$} \\
\hline & average & {$[ \pm \mathbf{E T}]$} & average & {$[ \pm \mathbf{E T}]$} & average & {$[ \pm \mathbf{E T}]$} \\
\hline $1[\mathrm{~N}=554]$ & -0.07 & {$[ \pm 0.56]$} & -0.05 & {$[ \pm 0.40]$} & -0.10 & {$[ \pm 0.77]$} \\
\hline $2[\mathrm{n}=283]$ & -0.29 & {$[ \pm 2.77]$} & -0.12 & {$[ \pm 2.43]$} & -0.63 & {$[ \pm 3.31]$} \\
\hline $3[n=285]$ & 0.42 & {$[ \pm 4.67]$} & 0.91 & {$[ \pm 3.49]$} & -0.55 & {$[ \pm 6.32]$} \\
\hline $4[n=254]$ & 1.27 & {$[ \pm 3.94]$} & 1.37 & {$[ \pm 3.93]$} & 1.07 & {$[ \pm 3.98]$} \\
\hline $5[\mathrm{n}=243]$ & 1.91 & {$[ \pm 4.43]$} & 2.13 & {$[ \pm 4.58]$} & 1.48 & {$[ \pm 4.11]$} \\
\hline $6[n=228]$ & 2.75 & {$[ \pm 4.85]$} & 3.24 & {$[ \pm 4.83]$} & 1.78 & {$[ \pm 4.77]$} \\
\hline
\end{tabular}

Table 3. Analysis of factors associated with weight gain during tuberculosis treatment of tuberculosis and HIV co-infected patients at the Conakry University Hospital of Conakry.

\begin{tabular}{|c|c|c|c|c|c|c|c|c|c|}
\hline \multirow{3}{*}{ Variables } & \multicolumn{3}{|c|}{ Weight Gain } & \multicolumn{3}{|c|}{ Bivariate Analyse } & \multicolumn{3}{|c|}{ Multivariate Analyse } \\
\hline & \begin{tabular}{|l|} 
Total \\
\end{tabular} & $\leq 5 \%$ & $>5 \%$ & \multirow{2}{*}{ OR } & \multirow{2}{*}{ IC } & \multirow{2}{*}{ p-value } & \multirow{2}{*}{ Adjusted OR } & \multirow{2}{*}[95\%\mathrm{CI}]{} & \multirow{2}{*}{ p-value } \\
\hline & $\mathrm{N}=\mathbf{2 2 8}$ & $n=114[\%]$ & $n=114[\%]$ & & & & & & \\
\hline Pneumology & 214 & $110[51.4]$ & $104[48.6]$ & 1 & Ref & - & 1 & Ref & - \\
\hline SMIT & 14 & 4 [28.6] & $10[71.4]$ & 2.64 & {$[0.80-8.69]$} & 0.09 & 3.81 & $1.08-13.45$ & 0.04 \\
\hline Sex & - & - & - & - & - & - & - & - & - \\
\hline Woman & 118 & $61[51.7]$ & $57[48.3]$ & 1 & Ref & - & - & - & - \\
\hline Man & 110 & $57[51.8]$ & $57[51.8]$ & 1.15 & {$[0.68-1.94]$} & 0.59 & - & - & - \\
\hline Age range & - & - & - & - & - & - & - & - & - \\
\hline$\leq 35$ ans & 142 & $69[48.6]$ & $73[51.4]$ & 1.16 & {$[0.68-1.98]$} & 0.58 & - & - & - \\
\hline$>35$ ans & 86 & $45[52.3]$ & $41[47.7]$ & 1 & Ref & - & - & - & - \\
\hline Status matrimonial & - & - & - & - & - & - & - & - & - \\
\hline Married & 132 & $67[50.8]$ & 65 [49.2] & 1 & Ref & - & - & - & - \\
\hline Single & 96 & $47[49.0]$ & 49 [51.0] & 1.08 & {$[0.64-1.82]$} & 0.79 & - & - & - \\
\hline Have a job & - & - & - & - & - & - & - & - & - \\
\hline No & 65 & $36[55.4]$ & 29 [44.6] & 1 & Ref & - & - & - & - \\
\hline Yes & 162 & \begin{tabular}{|l|}
78 [48.1] \\
\end{tabular} & 84 [51.9] & 1.34 & {$[0.75-2.38]$} & 0.33 & - & - & - \\
\hline Smoker & - & - & - & - & - & - & - & - & - \\
\hline No & 168 & 88 [52.4] & 80 [47.6] & 1 & Ref & - & - & - & - \\
\hline Yes & 60 & \begin{tabular}{|l|}
$26[43.3]$ \\
\end{tabular} & 34 [56.7] & 1.44 & {$[0.79-2.6]$} & 0.23 & - & - & - \\
\hline Alcohol & - & - & - & - & - & - & - & - & - \\
\hline
\end{tabular}


(Table 3) contd.....

\begin{tabular}{|c|c|c|c|c|c|c|c|c|c|}
\hline \multirow{3}{*}{ Variables } & \multicolumn{3}{|c|}{ Weight Gain } & \multicolumn{3}{|c|}{ Bivariate Analyse } & \multicolumn{3}{|c|}{ Multivariate Analyse } \\
\hline & \multirow{2}{*}{\begin{tabular}{|c|} 
Total \\
$\mathbf{N}=228$ \\
\end{tabular}} & \multirow{2}{*}{\begin{tabular}{|c|}
$\leq 5 \%$ \\
$n=114[\%]$
\end{tabular}} & \multirow{2}{*}{\begin{tabular}{|c|}
$>5 \%$ \\
$n=114[\%]$ \\
\end{tabular}} & \multirow{2}{*}{ OR } & \multirow{2}{*}{ IC } & \multirow{2}{*}{ p-value } & \multirow{2}{*}{ Adjusted OR } & \multirow{2}{*}[95\%\mathrm{CI}]{} & \multirow{2}{*}{ p-value } \\
\hline & & & & & & & & & \\
\hline No & 216 & $111[51.4]$ & $105[48.6]$ & 1 & Ref & - & 1 & Ref & - \\
\hline Yes & 8 & $1[12.5 \%]$ & $7[87.5]$ & 7.4 & {$[0.9-61.17]$} & 0.06 & 10.33 & $1.20-89.16$ & 0,03 \\
\hline Nombre IO* & - & - & - & - & - & - & - & - & - \\
\hline$<2$ & 224 & $113[50.4]$ & $111[49.6]$ & 1 & Ref & - & - & - & - \\
\hline$\geq 2$ & 4 & $1[25.0]$ & $3[75.0]$ & 3.05 & {$[0.31-29.81]$} & 0.34 & - & - & - \\
\hline IBM in $\mathrm{kg} / \mathrm{m}^{2}$ & - & - & - & - & - & - & - & - & - \\
\hline$<18.5$ & 152 & 68 [44.7] & $84[55.3]$ & 1.89 & {$[1.08-3.32]$} & 0.03 & 2.72 & $1.43-5.17$ & 0.002 \\
\hline$\geq 18.5$ & 76 & $46[60.5]$ & $30[39.5]$ & 1 & Ref & - & 1 & Ref & - \\
\hline CD4 Count in cell $/ \mathrm{mm}^{3}$ & - & - & - & - & - & - & - & - & - \\
\hline$\leq 200$ & 102 & $49[48.0]$ & $53[52.0]$ & 0.78 & {$[0.45-1.37]$} & 0.50 & - & - & - \\
\hline$>200$ & 98 & $53[54.1]$ & $45[45.9]$ & 1 & Ref & - & - & - & - \\
\hline Missing & 28 & $12[42.9]$ & $16[57.1]$ & 1.23 & {$[0.53-2.86]$} & - & - & - & - \\
\hline Antiretroviral therapy & - & - & - & - & - & - & - & - & - \\
\hline Yes & 221 & $112[50.7]$ & $109[49.3]$ & 1 & Ref & - & - & - & - \\
\hline No & 7 & $2[28.6]$ & $5[71.4]$ & 2.57 & {$[0.49-13.52]$} & 0.27 & - & - & - \\
\hline Tuberculosis form & - & - & - & - & - & - & - & - & - \\
\hline Pulmonary & 208 & $107[51.4]$ & $101[48.6]$ & - & Ref & 0.16 & 1 & Ref & - \\
\hline Extrapulmonary & 20 & $7[35.0]$ & $13[65.0]$ & 1.97 & {$[0.76-5.13]$} & - & 3.27 & $1.14-9.33$ & 0.03 \\
\hline
\end{tabular}

\section{DISCUSSION}

In the Guinean context, a study carried out in the two national reference services (Pneumophtisiology Department and the Infectious and Tropical Diseases Department of the Conakry University Hospital Center) has generated evidence applicable to the public health structures of the national territory to adjust medical practices and guide the planning of interventions for the management of TB/HIV co-infections. This study has made it possible to estimate the proportion of weight gain of $5 \%$ at the end of a 6 -month tuberculosis treatment in TB/HIV co-infected patients.

Women represented $52.5 \%$ of the study population. This percentage is comparable to that of women in the general population of people living with HIV in the Republic of Guinea, which is $58 \%$ [10]. This predominance of women coinfected with TB/HIV has also been observed in Uganda [11], where a proportion of $62 \%$ of women was reported in the TB/HIV co-infected population. This result is believed to be explained by the high prevalence of HIV, the infection underlying the re-emergence of TB, observed among women in Guinea, but also by the steady increase in the number of women tested for HIV through the prevention of mother-tochild transmission of HIV programs in Guinea. Thus, by national standards, knowledge of HIV+ status suggests a systematic search for TB infection.

The population in this study was relatively young with an average age of $35.6 \pm 11.3$ years; this is comparable to the data from the Demographic and Health Survey [12] which shows a predominantly young Guinean population. This result is also comparable to that of the study conducted in Ethiopia [13], which reported an average age of $31.55 \pm 15.79$ years. However, our result is lower than that of the study conducted in Burkina Faso [14], where the average age was $43.6 \pm 15.3$ years. These differences could be explained by the structure of the general population from which TB/HIV co-infected patients come.

The prevalence of undernutrition among TB/HIV coinfected patients before treatment was high (63.7\%). This result is higher than that of Sidibé Set coll [15] who found a 19.6\% prevalence of malnutrition among people living with HIV/AIDS in the Ratoma community medical center in Guinea.

Lower prevalences have been reported in West Africa, particularly by Benzekri et al. [16]. In Senegal (19.2\% in Dakar, and 26.3\% in Ziguinchor) and at the Centre intégré de recherche bioclinique d'Abidjan (16.3\%) [17]. In contrast, studies conducted in Guinea-Bissau in 2013 [18] and Ethiopia in 2019 [13] respectively reported higher undernutrition prevalences of 51.9 and $62.2 \%$. This difference could be explained, contrary to these authors, by the fact that we collected patients co-infected with TB/HIV who were highly immunocompromised (CD4 less than or equal to 200 those $/ \mathrm{mm}^{3}$ ) and with one or more opportunistic infections. These differences could also be attributed to the different socio-economic and nutritional characteristics and lifestyle of the countries' populations.

At the end of our study, nearly one-third of our patients had an unfavorable outcome, more than half of whom died. Zachariah [19] in their study found early mortality of $8 \%$ in the first 4 weeks of TB treatment. Among the risk factors for mortality, the authors noted age over 35 years, the severity of malnutrition, and HIV status [19]. In our context, the association of an unfavorable evolution with certain basic clinical-biological parameters including the presence of more than one opportunistic infection, CD4 count, and being under antiretroviral therapy should attract our attention. These factors would likely be related to the consequences of late detection of HIV-infected individuals. Poverty, patient education, and the stigma associated with HIV infection and tuberculosis are 
factors that could influence the outcome of treatment for these patients.

Concerning the weight evolution during our study, the loss of sight or deceased shows no weight increase until the second month. Similar results have been found by other authors [20 22]. According to Bernabe [22], after 4 months, a patient cured of Tuberculosis gained an average of $3 \mathrm{~kg}(\mathrm{p}, 0.001)$, while those who had failed gained only $0.2 \mathrm{~kg}(\mathrm{p}=0.02)$. The study found that nearly half $(48.20 \%)$ of the TB/HIV co-infected patients had gained at least 5\% weight after six [6] months of anti-TB treatment; this is almost similar to the results of a study conducted by Gler et al. In the Philippines in 2013, where the sensitivity of a 5\% weight gain in the first 3 months of treatment to predict a good outcome was 50\% [9]. However, our result is lower than those reported by several other studies at the end of six months of anti-TB treatment. These include the Jørstad et al. study at Mnazi Mmoja Hospital in Zanzibar (83\%) [23] and the Phan et al. study in Houston, USA in 2020 $(62.4 \%)$ [21]. The difference in results between these studies may be due to differences in methodological approaches on the one hand, and in the package of care for TB/HIV co-infected patients by country on the other hand. Thus, the study conducted in the USA [21] had excluded co-infections with HIV. With regard to the package of care for TB/HIV coinfection, it should be noted that in Guinea, there are no public health facilities that provide food to HIV-infected adults. Access to food for PLHA remains difficult; more than half of the patients develop their food survival strategies and only $9.2 \%$ of PLHA receive nutritional assistance according to some authors. However, there are some NGOs that offer free Plumpy'Nut to HIV-infected patients $[12,14]$. The establishment of a nutrition unit in these public services with a minimum package including an assessment of nutritional status and provision of therapeutic food and supplementation could improve the quality of life of these TB/HIV co-infected patients in Guinea.

In the present study, weight gain after 6 months of treatment was significantly associated with the treatment site and form of Tuberculosis in the co-infected patients. Other authors reported that weight gain at the end of treatment was independently associated with treatment success [20].

In the context of resource-limited countries, weight assessment could be an easy, inexpensive, and useful form of predicting the outcome of TB treatment in HIV-TB patients.

One of the strengths of this study is that it was conducted on a large cohort of subjects (562 TB/HIV co-infected patients). Another strength of the study is that more than half of the patients included were malnourished prior to initiation of TB treatment, which represents a statistically reasonable power to detect an association between weight gain during six months of TB treatment [6].

Nevertheless, this study has limitations that should be recalled. First, it is a retrospective study based on archived records of patients co-infected with HIV and tuberculosis. On this point, the poor archiving conditions did not facilitate the collection of a number of variables. Second, there was a lack of information in the patient records on socio-economic aspects that could be explanatory factors for weight gain during tuberculosis treatment. Third, the lack of data on dietary or nutritional intake during treatment does not control the confusion that treatment may cause in estimating weight gain.

\section{CONCLUSION}

Patients newly diagnosed with HIV co-infected tuberculosis at the CHU in Conakry are often malnourished before tuberculosis treatment is started. Changes in weight may be an important determinant of tuberculosis treatment outcomes. Weight gain during therapy appears to be a reliable indicator of overall treatment response. Further prospective studies with standardized measures taking into account factors such as socioeconomic factors, co-morbidities, CD4 counts, and nutritional composition, biological outcomes, are needed to further enrich the knowledge on weight gain during TB treatment in TB/HIV infected patients in Guinea.

\section{ETHICAL STATEMENT}

This study was conducted in compliance with good clinical practices and the declaration of Helsinki principles. In accordance with the French Public Health Law, formal approval from. Ethics committee was not required for this type of study.

\section{CONSENT FOR PUBLICATION}

Not applicable.

\section{STANDARDS OF REPORTING}

The manuscript was prepared in accordance with STROBE guidelines.

\section{AVAILABILITY OF DATA AND MATERIAL}

The data are available from the corresponding author; it may be available after a reasonable request.

\section{FUNDING}

None.

\section{CONFLICT OF INTEREST}

The authors confirm that this article's content has no conflicts of interest.

\section{ACKNOWLEDGEMENTS}

We would like to thank the health personnel of the infectious diseases and pneumology departments of Conakry for the follow-up of patients and the proper completion of the files of patients treated in the departments.

\section{REFERENCES}

[1] Shah S, Whalen C, Kotler DP, et al. Severity of human immunodeficiency virus infection is associated with decreased phase angle, fat mass and body cell mass in adults with pulmonary tuberculosis infection in Uganda. J Nutr 2001; 131(11): 2843-7. [http://dx.doi.org/10.1093/jn/131.11.2843] [PMID: 11694606]

[2] Wejse C, Patsche CB, Kühle A, et al. Impact of HIV-1, HIV-2, and HIV-1+2 dual infection on the outcome of tuberculosis. Int J Infect Dis 2015; 32: 128-34

[http://dx.doi.org/10.1016/j.ijid.2014.12.015] [PMID: 25499041] 
[3] Organization WH. others Gear up to end TB: introducing the end TB strategy 2015.

[4] van Lettow M, Harries AD, Kumwenda JJ, Zijlstra EE, Clark TD, Taha TE, et al. Micronutrient malnutrition and wasting in adultswithpulmonarytuberculosiswith and without HIV co-infection in Malawi 2004. Available from: http://bmcinfectdis.biomedcentral.com/articles/10.1186/1471-2334-4-6 1

[5] Woodd SL, Kelly P, Koethe JR, Praygod G, Rehman AM, Chisenga $\mathrm{M}$, et al. Risk factors for mortalityamongmalnourished HIVinfectedadultseligible for antiretroviraltherapy. BMC Infect Dis [Internet] 2016. Available from: http://bmcinfectdis.biomedcentral.com/articles/10.1186/s12879-016-1 894-3

[6] Maro I, Lahey T, MacKenzie T, et al. Low BMI and falling BMI predict HIV-associated tuberculosis: a prospective study in Tanzania. Int J Tuberc Lung Dis 2010; 14(11): 1447-53.

[PMID: 20937186]

[7] Jeremiah K, Denti P, Chigutsa E, et al. Nutritional supplementation increases rifampin exposure among tuberculosis patients coinfected with HIV. Antimicrob Agents Chemother 2014; 58(6): 3468-74. [http://dx.doi.org/10.1128/AAC.02307-13] [PMID: 24709267]

[8] Ministère de la Santé et de l'Hygiene Publique. Programme National de Lutte Anti-Tuberculeuse. Guinée. Guide de prise en charge de la Tuberculose pharmacoresistante. Conakry Ministère de la Santé et de l'Hygiene Publique 2014; 1-60.

[9] Gler MT, Guilatco R, Caoili JC, Ershova J, Cegielski P, Johnson JL. Weight gain and response to treatment for multidrug-resistant tuberculosis. Am J Trop Med Hyg 2013; 89(5): 943-9. [http://dx.doi.org/10.4269/ajtmh.13-0011] [PMID: 24019430]

[10] Billong S. Analyse du profil épidemiologique et de la réponse programmatique du VIH en Guinée 2017; 1-26.

[11] Mupere E, Malone L, Zalwango S, et al. Wasting among Uganda men with pulmonary tuberculosis is associated with linear regain in lean tissue mass during and after treatment in contrast to women with wasting who regain fat tissue mass: prospective cohort study. BMC Infect Dis 2014; 14(1): 24.

[http://dx.doi.org/10.1186/1471-2334-14-24] [PMID: 24410970]

[12] Institut national de statistique de Guinée. Measure DHS. In : Enquête démographique et de sante' et à indicateurs multiples [EDS-MICS]. Conakry 2012; 1-530.

[13] Hussien B, Hussen MM, Seid A, Hussen A. Nutritional deficiency and associated factors among new pulmonary tuberculosis patients of Bale Zone Hospitals, southeast Ethiopia. BMC Res Notes 2019; 12(1): 751. [http://dx.doi.org/10.1186/s13104-019-4786-y] [PMID: 31744538]

[14] Musuenge BB, Poda GG, Chen P-C. Nutritional Status of Patients with Tuberculosis and Associated Factors in the Health Centre Region of Burkina Faso. Nutrients 2020; 12(9): 2540.

[http://dx.doi.org/10.3390/nu12092540] [PMID: 32825756]

[15] Sidibé S, Magassouba AS, Delamou A, Magaboussa FB, Sandouno SD, Kra KÉ, et al. Nutritionalstatus of people living with HIV/AIDS in the Ratomacommunitymedical center [Republic of Guinea]. Médecine Santé Trop 2017; 77-81.

[16] Benzekri NA, Sambou J, Diaw B, Sall EHI, Sall F, Niang A, et al. High Prevalence of Severe Food Insecurity and Malnutrition among HIV-InfectedAdults in Senegal, West Africa. In: Landay A, éditeur PLOS ONE. 2015; 10: p. (11)e0141819.

[17] Food and Nutrition Technical Assistance I.I.. Project [FANTA-2] Rapport de l'analyse situationnelle sur l'inte'gration de la nutrition et l'alimentation dans les programmes de prise en charge du PVVIH en vue de pre'parer la mise en oeuvre du «Food By Prescription [FBP]» ou «Alimentation sous Prescription Me'dicale [APM]» en Co^te d'Ivoire. Washington DC: FANTA-2. FHI 360. 2014

[18] Ministère de la Santé publique, République de Guinée-Bissau. Politique nationale de nutrition 2013.http://scalingupnutrition.org/ wpcontent/uploads/2014/03/politique-nationale-nutrition.fin_.fr_pdf

[19] Zachariah R, Spielmann M P. Moderate to severe malnutrition in patients withtuberculosisis a risk factor associatedwithearlydeath. Trans R Soc Trop Med Hyg Transactions of the Royal Society of Tropical Medicine and Hygiene 96(3): 291-4.

[20] Krapp F, Véliz JC, Cornejo E, Gotuzzo E, Seas C. 2008. Available from:

https://www.ingentaconnect.com/content/iuatld/ijtld/2008/00000012/0 0000010/art00011

[21] Phan MN, Guy ES, Nickson RN, Kao CC. Predictors and patterns of weight gain during treatment for tuberculosis in the United States of America. Int J Infect Dis 2016; 53: 1-5

[http://dx.doi.org/10.1016/j.ijid.2016.09.006] [PMID: 27693292]

[22] Bernabe-Ortiz A, Carcamo CP, Sanchez JF, Rios J. Weight variation over time and its association with tuberculosis treatment outcome: a longitudinal analysis. PLoS One 2011; 6(4)e18474

[http://dx.doi.org/10.1371/journal.pone.0018474] [PMID: 21494617]

[23] Jørstad MD, Dyrhol-Riise AM, Aßmus J, Marijani M, Sviland L, Mustafa T. Evaluation of treatment response in extrapulmonary tuberculosis in a low-resource setting. BMC Infect Dis 2019; 19(1): 426.

[http://dx.doi.org/10.1186/s12879-019-4034-z] [PMID: 31096926]

\section{C) 2021 Sow et al.}

This is an open access article distributed under the terms of the Creative Commons Attribution 4.0 International Public License (CC-BY 4.0), a copy of which is available at: https://creativecommons.org/licenses/by/4.0/legalcode. This license permits unrestricted use, distribution, and reproduction in any medium, provided the original author and source are credited. 